\title{
AVALIAÇÃO AGRONÔMICA DE HÍBRIDOS DE SORGO GRANÍFERO EM DIFERENTES REGIÕES PRODUTORAS DO BRASIL
}

\author{
JANEO EUSTÁQUIO DE ALMEIDA FILHO ${ }^{1}$, FLÁVIO DESSAUNE TARDIN² ${ }^{2}$ ROGÉRIO FIGUEIREDO \\ DAHER $^{1}$, KARLA JORGE DA SILVA ${ }^{2}$, JOÃO BATISTA XAVIER NETO ${ }^{3}$, EDSON BASTOS ${ }^{4}$, VINÍCIUS \\ DA SILVA LOPES ${ }^{3}$,TATIANE DA COSTABARBÉ ${ }^{1}$ e CÍCERO BESERRA DE MENEZES ${ }^{2}$
}

\begin{abstract}
${ }^{1}$ Universidade Estadual do Norte Fluminense Darcy Ribeiro Reitoria, Campos dos Goytacazes, RJ, Brasil, janeo.eustaquio@ymai.com ${ }^{2}$ Embrapa Milho e Sorgo,Sete Lagoas,MG,Brasil,flavio.tardin@embrapa.br,karla.js@hotmail.com, cicero.menezes@embrapa.br ${ }^{3}$ Universidade Federal de Uberlândia, Uberlândia, MG, Brasil, jbxneto@hotmail.com, viniciuslope@yahoo.com.br

${ }^{4}$ Embrapa Meio Norte, Teresina, PI, Brasil, edson.bastos@embrapa.br
\end{abstract}

Revista Brasileira de Milho e Sorgo, v.13, n.1, p. 82-95, 2014

\begin{abstract}
RESUMO - A cultura do sorgo granífero possui grande relevância no cenário agrícola brasileiro por ser mais uma alternativa de cultivo em condição de safrinha ou em regiões onde o déficit hídrico impossibilita o cultivo de outros cereais. Este trabalho avaliou 25 híbridos simples de sorgo granífero, sendo 22 híbridos pré-comerciais da Embrapa Milho e Sorgo e três cultivares comerciais. Esses híbridos foram analisados em nove locais de regiões produtoras dessa cultura, sob o delineamento de blocos ao acaso, e as características analisadas foram altura, florescimento e rendimento de grãos. Os contrastes de médias foram analisados pela DMS do teste de Tukey. A altura elevada observada para os híbridos 1G282 e 0307689 alertam para cautela de uso destes em ambientes passíveis de ventos fortes, pela possibilidade de acamamento e quebramento de plantas com consequentes perdas na colheita. A quantidade de dias para o florescimento não foi limitante para nenhum genótipo. Entretanto, vários híbridos pré-comerciais se mostraram mais precoces que os comerciais. Considerando a adaptabilidade e a estabilidade pelo método de Annicchiarico, os híbridos 1G282, BRS 308 e 0009061 foram os genótipos que mais se destacaram no rendimento de grãos. Os híbridos 0307131, 0307651 e 0307071 se destacaram agronomicamente em Teresina, PI. Os resultados sugerem novas avaliações para uma recomendação segura dos híbridos mais adaptados para cada região.
\end{abstract}

Palavras-chaves: Sorghum bicolor; desempenho agronômico; estabilidade e adaptabilidade.

\section{AGRONOMIC EVALUATION OF GRAIN SORGHUM HYBRIDS, CULTIVATED ON SECOND SEASON IN DIFFERENT REGIONS OF BRAZIL}

\begin{abstract}
The sorghum is an important crop in Brazil because is an alternative crop for the cultivation offseason or in regions where the production of other cereals is limited by water deficit. This work evaluated 25 simple hybrids of grain sorghum, 22 pre-commercial hybrids of Embrapa Milho e Sorgo and three commercial cultivars. These hybrids were evaluated in nine producing regions using a randomized block design. The characteristics evaluated were height, grain yield and flowering. The means were analyzed by DMS of Tukey's test. The high height observed for the hybrids 0307689 and $1 \mathrm{G} 282$ indicates a restriction in the utilization in environments subject to high winds, because of the possibility of lodging and break of the plants, with consequent losses at harvest. The number of days for flowering was not limiting for any genotype; however, several pre-commercial hybrids were earlier than the cultivars. Considering stability and adaptability, the hybrids 1G282, BRS 308 and 0009061 presented the highest grain yield. Hybrids 0307131, 0307651 and 0307071 presented higher performance in Teresina. The results suggest the need for further assessments for recommending the most suitable hybrids for each region.
\end{abstract}

Key words: Sorghum bicolor; agronomic performance; stability and adaptability.

Versão impressa ISSN 1676-689X / Versão on line ISSN 1980-6477 http://www.abms.org.br 
O Brasil é um país privilegiado pela possibilidade de realização de duas safras por ano em várias regiões. A segunda safra, também chamada de safrinha, ocorre aproveitando as chuvas do final do verão e início do outono e, com isso, a exploração agrícola, nessa época, requer um sistema de produção bem planejado, com uso de espécies adaptadas a essa condição ambiental que, geralmente, apresenta distribuição de chuvas instáveis e, muitas vezes, insuficientes.

Assim, com a finalidade de buscar maior rentabilidade por área, o cultivo do sorgo é alavancado para a exploração na safrinha, uma vez que o sorgo possui importantes características xerófitas que tornam propício seu uso nessa época (Olembo et al. (2010).

O sorgo é considerado o quinto cereal mais importante do mundo, sendo uma importante fonte calórica na alimentação humana em países em desenvolvimento (Mutisya et al., 2009). Contudo, no Brasil, seu uso está destinado basicamente a confecção de rações animais (Sindirações, 2013), uma vez que substituição do milho pelo sorgo não acarreta prejuízos nutricionais (Garcia et al. 2005; Globesso et al. 2008) e o sorgo no Brasil é cotado a $80 \%$ do preço do milho (Conab, 2013).

Apesar da importância da cultura do sorgo, são observadas poucas informações científicas na literatura, tanto no que se refere ao manejo (Albuquerque et al., 2011; Goes et al., 2011), quanto no que se refere à avaliação de genótipos promissores, sendo a maior parte das informações acerca de cultivares levadas ao agricultor pela iniciativa das empresas que comercializam as sementes.

Para o estabelecimento de um sistema de produção, além de se utilizarem práticas culturais adequadas, é fundamental a escolha de cultivares adaptadas às diferentes condições de cultivo. Para auxiliar nessa escolha, são realizados os chamados ensaios de competição de cultivares. Trabalhos nesse sentido já foram realizados por Albuquerque et al. (2011); Silva et al. (2009); Heckeler (2002) e Mariguele \& Silva (2002). A Embrapa Milho e Sorgo realiza, todos os anos, ensaios de competição de cultivares em várias regiões do país, avaliando vários híbridos simples de sorgo para suprimento da demanda de cultivares adaptadas e de informações acerca dessa cultura.

Uma dificuldade, frequentemente observada em ensaios de competição de cultivares, é a resposta desigual dos genótipos diante da variação ambiental, tornando a recomendação de cultivares um desafio, pois o desempenho superior de um genótipo não se mantém em todos os ambientes. Para lidar com esse percalço, a estratégia recomendada pela literatura é o uso de genótipos com adaptabilidade geral e estabilidade agronômica (Cruz \& Carneiro 2006).

Com isso, o objetivo deste trabalho foi avaliar a resposta de híbridos comerciais e experimentais de sorgo granífero nas diferentes condições de ambiente de áreas de produção da cultura no Brasil e, consequentemente, obter informações que possibilitem a recomendação de cultivares.

Foram utilizados dados de ensaios conduzidos pela Embrapa Milho e Sorgo em várias localidades produtoras do país (Tabela 1). Os ensaios foram implantados entre o final do mês de fevereiro e o início do mês de março de 2011, com exceção do experimento conduzido no município de Campos dos Goytacazes, RJ, que foi implantado no dia 15/04/2011. A época de implantação dos experimentos caracteriza o período da safrinha na maior parte dos locais avaliados, sendo que não se encaixam, nesse âmbito, apenas os locais de Teresina, PI e Campos dos Goytacazes, RJ. Os dados climáticos 
TABELA 1. Descrição geográfica dos municípios avaliados e características avaliadas em cada local.

\begin{tabular}{|c|c|c|c|c|}
\hline \multirow{2}{*}{ Locais } & \multirow{2}{*}{ Altitude $(\mathrm{m})^{1}$} & \multirow{2}{*}{ Latitude } & \multicolumn{2}{|c|}{ Característica $^{2}$} \\
\hline & & & FLO & RG \\
\hline Água Comprida, $\mathrm{MG}$ & 535 & $-20^{\circ} 03^{\prime}$ & $\mathrm{X}$ & $\mathrm{X}$ \\
\hline Campos dos Goytacazes, RJ & 11 & $-21^{\circ} 45^{\prime}$ & $\mathrm{X}$ & \\
\hline Guaíra, SP & 507 & $-20^{\circ} 19^{\prime}$ & $\mathrm{X}$ & $\mathrm{X}$ \\
\hline Itumbiara, GO & 500 & $-18^{\circ} 24^{\prime}$ & $\mathrm{X}$ & \\
\hline Montividiu, GO & 833 & $-17^{\circ} 26^{\prime}$ & & $X$ \\
\hline Rio Verde, GO & 754 & $-17^{\circ} 47^{\prime}$ & & $\mathrm{X}$ \\
\hline Sete Lagoas, MG & 773 & $-19^{\circ} 28^{\prime}$ & $\mathrm{X}$ & $\mathrm{X}$ \\
\hline Teresina, PI & 81 & $-5^{\circ} 05^{\prime}$ & $\mathrm{X}$ & $\mathrm{X}$ \\
\hline Vilhena, RO & 577 & $-12^{\circ} 44^{\prime}$ & $\mathrm{X}$ & $\mathrm{X}$ \\
\hline
\end{tabular}

disponíveis da época da experimentação podem ser observados na Figura 1.

O delineamento utilizado foi o de blocos ao acaso, com três repetições e 25 híbridos. Destes, 22 são híbridos simples pré-comerciais, oriundos do Núcleo de Recursos Genéticos e Desenvolvimento de Cultivares da Embrapa Milho e Sorgo, e três são as cultivares comerciais 1 G282, BRS 308 e BRS 330.

As parcelas experimentais foram constituídas por quatro linhas de $5 \mathrm{~m}$, sendo utilizadas, apenas, as duas linhas centrais como área útil da parcela. $\mathrm{O}$ espaçamento entre linhas de $0,5 \mathrm{~m}$, conforme preconiza Albuquerque et al. (2011), e o espaçamento de $0,1 \mathrm{~m}$ entre plantas totalizaram um estande médio de 200.000 plantas ha $^{-1}$, conforme o trabalho de Silva et al. (2009). Lopes et al. (2005) recomendam parcelas de $3,2 \mathrm{~m}^{2}$ para avaliação de rendimento de grãos de sorgo granífero.

As características avaliadas foram: a) altura de plantas, medindo-se o comprimento entre o colo da planta e o ápice da panícula no momento da maturação fisiológica; b) quantidade de dias entre a semeadura e o florescimento, considerando o florescimento da parcela quando, em mais de $50 \%$ das plantas, as flores do terço médio da panícula entraram em antese; e c) rendimento de grãos, em que foram colhidos os grãos da parcela e, subsequentemente, foi mensurada a umidade dessas, para posterior correção para a umidade de $13 \%$, segundo a fórmula $M_{c}$ $=M_{o}\left(100-u_{0}\right) 87^{-1}$; sendo: $M_{c}$ e $M_{o}$ massa corrigida e observada, respectivamente; $\mathrm{u}_{0}$ : umidade observada (Cromarty et al., 1985). Em alguns ambientes, não foram avaliadas todas as características, conforme apresentado na Tabela 1.

Os tratos culturais foram realizados de acordo com o recomendado por Rodrigues (2010). A irrigação foi plena em Campos dos Goytacazes, RJ e utilizada apenas para estabelecimento inicial do experimento em Sete Lagoas, MG, enquanto que, no restante dos ambientes, não foi realizada irrigação.

Para a avaliação estatística dos resultados, foi realizada, inicialmente, uma análise de variância para cada experimento de forma independente, segundo o modelo: $\mathrm{Y}_{\mathrm{ij}}=\mu+\mathrm{G}_{\mathrm{i}}+\mathrm{B}_{\mathrm{j}}+\varepsilon_{\mathrm{ij}}$, sendo $\mathrm{Y}_{\mathrm{ij}}$ : valor da determinada característica observada na parcela que recebeu o genótipo i, alocado no bloco $\mathrm{j}$; $\mu$ : constante 
geral; $\mathrm{G}_{\mathrm{i}}$ : efeito fixo do i-ésimo genótipo; $\mathrm{B}_{\mathrm{j}}$ : efeito aleatório do j-ésimo bloco; $\mathrm{B}_{\mathrm{j}} \sim \operatorname{NID}\left(0, \sigma^{2} b\right) ; \varepsilon_{\mathrm{ij}}$ efeito aleatório do erro experimental observado na parcela ij; $\varepsilon_{\mathrm{ij}} \sim \operatorname{NID}\left(0, \sigma^{2}\right)$.

Em seguida, verificou-se a homogeneidade da variância residual dos experimentos, condição fundamental para realização da análise de variância conjunta, pela razão entre o maior e o menor quadrado médio do erro, de acordo com o proposto por Gomes (2009). Segundo esse autor, se a relação entre a variância residual entre os experimentos for inferior a sete, a análise de variância conjunta pode ser realizada.

O modelo estatístico adotado para análise de variância conjunta, considerando todos os experimentos, foi: $Y_{i j k}=\mu+B_{k}\left(A_{j}\right)+G_{i}+A_{j}+G_{i} A_{j}+\varepsilon_{i j k}$; sendo: $B_{k}\left(A_{j}\right)$ : efeito aleatório do bloco $k$ no ambiente $\mathrm{j} ; \mathrm{B}_{\mathrm{k}}\left(\mathrm{A}_{\mathrm{j}}\right) \sim \operatorname{NID}\left(0, \sigma^{2} \mathrm{~B}(\mathrm{~A})\right) ; \mathrm{A}_{\mathrm{j}}$ : efeito aleatório do j-ésimo ambiente; $A_{j} \sim N I D\left(0, \sigma^{2} A\right) ; G_{i} A_{j}$ : efeito aleatório da interação entre o genótipo i com o ambiente $\mathrm{j} ; \mathrm{G}_{\mathrm{i}} \mathrm{A}_{\mathrm{j}} \sim \mathrm{NID}\left(0, \sigma^{2} \mathrm{GA}\right)$.

A comparação das médias foi realizada utilizando-se a diferença mínima significativa (DMS) obtida pelo teste de Tukey a 5\% de probabilidade.

Para a avaliação da adaptabilidade e estabilidade do rendimento de grãos, foi utilizado o método proposto por Annicchiarico (1992). Esse autor propõe o denominado índice de confiança, que consiste no risco do uso de um determinado genótipo em relação a qualquer um dos demais em avaliação. Esse índice indica o valor percentual esperado em relação à média ambiental do uso desse determinado genótipo no determinado ambiente, sendo dado por:

$$
\mathrm{I}_{\mathrm{i}}=\overline{\mathrm{p}}_{\mathrm{i} .}+\mathrm{Z}_{(1-\propto)} \mathrm{S}_{\mathrm{i}}\left(\mathrm{p}_{\mathrm{ij}}\right)
$$

onde: $\mathrm{p}_{\mathrm{ij}}=100 \mathrm{y}_{\mathrm{ij}} / \overline{\mathrm{y}}_{\mathrm{j}}$; representa o valor percentual do genótipo i no local $\mathrm{j}$ em relação à média ambiental desse local; $\mathrm{p}_{\mathrm{i}}$ : é a média dos valores percentuais do genótipo $\mathrm{i} ; \mathrm{s}_{\mathrm{i}}\left(\mathrm{p}_{\mathrm{ij}}\right)$ : é o desvio padrão dos valores percentuais do genótipo $i ; Z_{(1-\alpha)}$ : é a probabilidade de obter genótipos com produtividade média relativa entre 0 e $(1-\alpha)$ para $\alpha=0,25$, considerando que a variável segue distribuição normal: $Z_{(1-\alpha)} \approx 0,2734$. Mais detalhes estão em Cruz \& Carneiro (2006).

As análises de variância e os testes de médias foram realizados utilizando-se o software Sisvar (Ferreira, 2008). Já a análise de estabilidade e adaptabilidade foi realizada por meio do software Genes (Cruz 2006).

Pelos coeficientes de variação, foi verificado que a qualidade experimental foi satisfatória para as características avaliadas em todos os experimentos (Tabela 2) (Gomes, 2009).

$\mathrm{Na}$ análise de variância (Anova), realizada em cada ambiente, foi observado que o efeito de híbridos não foi significativo a 5\% de probabilidade para altura de plantas em Água Comprida, MG, para florescimento em Itumbiara, GO, Sete Lagoas, MG e Teresina, PI e para rendimento de grãos em Água Comprida, MG e Montividiu, GO. Nas demais avaliações, o efeito de híbrido foi significativo, indicando que houve diferença entre os híbridos avaliados (Tabela 2).

Todos os locais foram considerados para realização da Anova conjunta para a característica rendimento de grãos. Entretanto, por não apresentar variância residual homogênea com os demais locais avaliados, o experimento de Teresina, PI não foi incluído na análise conjunta para florescimento, bem como a localidade de Itumbiara, GO não foi incluída na análise conjunta para altura (Gomes, 2009).

Considerando os resultados da análise de variância conjunta, em todas as características foi observado efeito significativo de híbridos, ambientes e 
TABELA 2. Resumo das análises de variâncias individuais para as variáveis altura de plantas, florescimento e produtividade de grãos nos locais Água Comprida, MG (AC), Campos dos Goytacazes, RJ (CG), Guaíra, SP (GUA), Itumbiara -GO (ITU), Montividiu, GO (MON), Rio Verde, GO (RV), Sete Lagoas, MG (SL), Teresina, PI (TER) e Vilhena, RO (VIL) em 2011.

\begin{tabular}{|c|c|c|c|c|c|c|c|c|c|}
\hline \multirow{2}{*}{ FV } & \multicolumn{9}{|c|}{ Quadrados médios para altura de plantas $(\mathrm{cm})$} \\
\hline & $\mathrm{AC}$ & CG & GUA & ITU & MON & RV & SL & TER & VIL \\
\hline Híbridos & 128,11 & 424,82 & 437,78 & 336,38 & 318,16 & 325,50 & 451,29 & 550,38 & 287,69 \\
\hline Erro & 112,82 & 38,86 & 95,07 & 3,89 & 41,19 & 42,64 & 97,88 & 77,13 & 87,61 \\
\hline C.V. $(\%)$ & 8,98 & 4,86 & 7,45 & 1,48 & 5,48 & 5,2 & 7,32 & 7,14 & 8,41 \\
\hline \multirow[t]{2}{*}{ p-valor } & 0,345 & $<0,01$ & $<0,01$ & $<0,01$ & $<0,01$ & $<0,01$ & $<0,01$ & $<0,01$ & $<0,01$ \\
\hline & \multicolumn{9}{|c|}{ Quadrados médios para florescimento (dias) } \\
\hline Híbridos & 2,10 & 8,01 & 6,17 & 8,83 & - & - & 1,97 & 15,57 & 10,64 \\
\hline Erro & 1,05 & 1,44 & 0,82 & 5,37 & - & - & 1,65 & 12,67 & 1,98 \\
\hline C.V. $(\%)$ & 1,68 & 1,77 & 1,52 & 3,52 & - & - & 1,90 & 6,28 & 2,58 \\
\hline \multirow[t]{2}{*}{ p-valor } & 0,021 & $<0,01$ & $<0,01$ & 0,071 & - & - & 0,293 & 0,146 & $<0,01$ \\
\hline & \multicolumn{9}{|c|}{ Quadrados médios para produtividade de grãos $\left(\mathrm{kg} \mathrm{ha}^{-1}\right)$} \\
\hline Híbridos & 369720,80 & - & 1635735,75 & - & 732799,11 & 441513,96 & 1377557,04 & 1000938,22 & 1552148,92 \\
\hline Erro & 471131,13 & - & 322858,63 & - & 437555,93 & 480928,05 & 450419,00 & 352017,51 & 296528,90 \\
\hline C.V. $(\%)$ & 17,96 & - & 14,48 & - & 20,26 & 11,79 & 16,38 & 9,34 & 15,56 \\
\hline p-valor & $\mathrm{F} \leq 1$ & - & $<0,01$ & - & 0,064 & $<0,01$ & $<0,01$ & $<0,01$ & $<0,01$ \\
\hline
\end{tabular}

C.V. (\%): Coeficiente de variação; $\mathrm{p}$-valor para o teste $\mathrm{F}$ do efeito de híbridos quando $\mathrm{F}>1$.

interação entre híbridos x ambientes, indicando que a resposta dos híbridos, para essas características, foi diferente diante da variação dos locais (Tabela 3). Resultados semelhantes foram obtidos por Silva et al. (2009) para todas essas características.

É interessante que cultivares de sorgo granífero apresentem altura entre $1 \mathrm{~m}$ e $1,5 \mathrm{~m}$ (Santos, 2003), uma vez que a colheita dessa cultura é realizada com implementos adaptados de outras culturas. Além disso, no melhoramento do sorgo granífero, procuram-se indivíduos menores que $1,5 \mathrm{~m}$ para evitar problemas de acamamento nas lavouras.

Pela análise das médias (Tabela 4), foi observado porte inferior a $1 \mathrm{~m}$ apenas com os híbridos 0307343 e 0307401, ambos em Vilhena, RO, com altura de $96,97 \mathrm{~cm}$. Entretanto, essas alturas não diferiram, estatisticamente, de $1 \mathrm{~m}$. O estresse hídrico ocorrido no final da fase vegetativa pode ter contribuído com as baixas alturas observadas nesse local (Figura 1).

Já a cultivar comercial $1 \mathrm{G} 282$ e o híbrido 0307689 foram os únicos que apresentaram altura, estatisticamente, superior a $150 \mathrm{~cm}$; em ambos os casos, em Itumbiara, GO. A alta disponibilidade hídrica provavelmente contribuiu com esse resultado (Figura 1).

Os genótipos 1G282 e 0307689 também apresentaram porte acima de $150 \mathrm{~cm}$ em outros locais, indicando que é necessária cautela ao cultivar esses genótipos em locais com incidência de ventos fortes, uma vez que o porte elevado torna o híbrido 
TABELA 3. Resumo das análises de variância conjunta para as características altura, florescimento e rendimento de grãos de experimentos com 25 híbridos de sorgo granífero avaliados em diferentes ambientes em 2011.

\begin{tabular}{lccccccccc}
\hline \multirow{2}{*}{ FV } & \multicolumn{3}{c}{ Altura $^{1}$} & \multicolumn{3}{c}{ Florescimento $^{2}$} & \multicolumn{3}{c}{ Rendimento de grãos $^{2}$} \\
\cline { 2 - 10 } & GL & QM & p-valor & GL & QM & p-valor & GL & QM & p-valor \\
\hline Blo(Amb) & 16 & $1,479,25$ & - & 12 & 2,86 & - & 14 & 2920365 & - \\
Híbrido (G) & 24 & 2121,62 & $<0,01$ & 24 & 21,17 & $<0,01$ & 24 & 1766757,31 & $<0,01$ \\
Ambiente (A) & 7 & 4648,77 & $<0,01$ & 5 & 2054,49 & $<0,01$ & 6 & 109611882,64 & $<0,01$ \\
GxA & 168 & 114,59 & $<0,01$ & 120 & 3,31 & $<0,01$ & 144 & 890609,41 & $<0,01$ \\
Erro & 384 & 74,15 & - & 288 & 2,05 & - & 336 & 401634,2 & - \\
\hline C.V. (\%) & & 6,96 & & & 2,28 & & & 14,38 &
\end{tabular}

${ }^{\mathrm{O}} \mathrm{O}$ local Itumbiara, GO não foi considerado, na análise conjunta, para altura, pois não apresentou variância residual homogênea com os demais locais; ${ }^{2} 0$ local Teresina, PI não foi considerado, na análise conjunta, para florescimento, pois não apresentou variância residual homogênea com os demais locais.

vulnerável ao acamamento e ao quebramento de plantas, com consequentes perdas na colheita.

Diante da análise das médias, considerando-se todos os locais, com exceção de Itumbiara, GO, que não foi englobado na análise de variância conjunta, foi verificado que nenhum híbrido apresentou altura estatisticamente inferior a $1 \mathrm{~m}$, nem superior a $1,5 \mathrm{~m}$, indicando que o propósito almejado pelo programa de melhoramento da Embrapa, no que se refere à altura do sorgo granífero, por enquanto está sendo atendido.

Em trabalhos de avaliação de cultivares de sorgo granífero, Silva et al. (2009) observaram intervalos de altura dentro da faixa preconizada por Santos (2003), enquanto Mariguele \& Silva (2002) observaram altura de híbridos de sorgo granífero no intervalo de 134 a 173 cm e Heckler (2002) observou cultivares com altura variando de 95 a $166 \mathrm{~cm}$.

Os resultados das análises da quantidade de dias da semeadura até o florescimento mostraram a existência de variabilidade entre genótipos e entre locais. A maior média para florescimento foi de 70,3 dias, com os genótipos 0307091 e BRS 308, ambos em Campos dos Goytacazes, RJ, enquanto a menor média foi de 51,33 dias, para o genótipo 0307511, em Vilhena, RO (Tabela 4).

A disponibilidade de cultivares com diferentes épocas para florescimento também é uma medida estratégica interessante, pois, se um produtor for realizar um plantio mais cedo, pode optar por uma cultivar de abertura de safra que tem ciclo mais tardio, pois esta tende a ser mais produtiva por ter a fase vegetativa mais longa.

Sobretudo, a busca por genótipos precoces é bastante válida, pois é interessante que a cultura fique menos tempo sujeita a um ambiente passível de estresse hídrico, como é o ambiente de safrinha. Silva et al. (2009) relatam que a colheita antecipada na época da safrinha permite maior flexibilidade nas negociações dos grãos, proporcionando maior rentabilidade com a produção. 

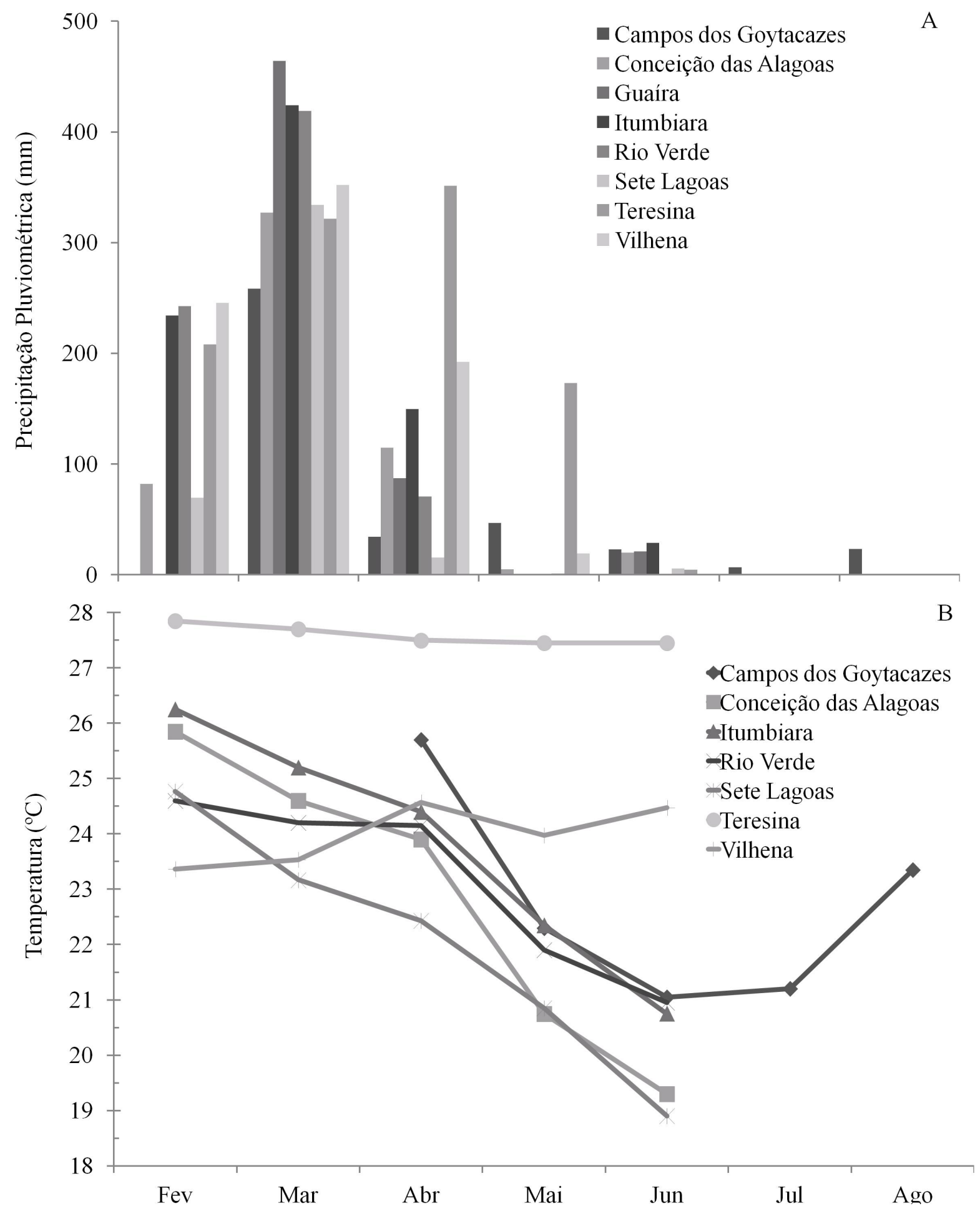

FIGURA 1. Dados meteorológicos de precipitação pluviométrica (A) e de temperatura média (B) dos ambientes avaliados. 
TABELA 4. Médias de 25 híbridos de sorgo granífero e diferenças mínimas significativas (DMS) pelo teste de Tukey a 5\% de significância para altura em cm nos locais Água Comprida, MG (AC), Campos dos Goytacazes, RJ (CG), Guaíra, SP (GUA), Itumbiara, GO (ITU), Montividiu, GO (MON), Rio Verde, GO (RV), Sete Lagoas, MG (SL), Teresina, PI (TER) e Vilhena, RO (VIL) em 2011.

\begin{tabular}{|c|c|c|c|c|c|c|c|c|c|c|c|}
\hline \multirow{2}{*}{ Híbridos } & \multicolumn{9}{|c|}{ Locais } & \multirow{2}{*}{ Média $^{+}$} & \multirow{2}{*}{ Média $^{+}$} \\
\hline & $\mathrm{AC}$ & $\mathrm{CG}$ & GUA & ITU & MON & $\mathrm{RV}$ & SL & TER & VIL & & \\
\hline 0009061 & 116,67 & 123,92 & 127,00 & 139,33 & 120,00 & 133,33 & 143,67 & 117,40 & 108,33 & 123,79 & 125,52 \\
\hline 0144013 & 120,00 & 126,00 & 128,67 & 136,67 & 113,33 & 125,00 & 127,67 & 122,93 & 113,33 & 122,12 & 123,73 \\
\hline 0307001 & 106,67 & 114,42 & 120,67 & 117,33 & 110,00 & 116,67 & 121,67 & 110,60 & 100,00 & 112,59 & 113,11 \\
\hline 0307047 & 113,33 & 119,67 & 125,00 & 120,33 & 115,00 & 120,00 & 125,33 & 121,40 & 110,00 & 118,72 & 118,90 \\
\hline 0307061 & 128,33 & 121,83 & 123,33 & 127,67 & 111,67 & 123,33 & 144,67 & 118,73 & 111,67 & 122,95 & 123,47 \\
\hline 0307063 & 118,33 & 125,22 & 122,00 & 130,00 & 110,00 & 118,33 & 124,33 & 118,00 & 101,67 & 117,24 & 118,65 \\
\hline 0307071 & 126,67 & 135,00 & 128,33 & 142,00 & 120,00 & 126,67 & 157,00 & 118,53 & 115,00 & 128,40 & 129,91 \\
\hline 0307087 & 116,67 & 139,83 & 120,00 & 133,33 & 130,00 & 125,00 & 134,67 & 122,33 & 113,33 & 125,23 & 126,13 \\
\hline 0307091 & 121,67 & 142,75 & 130,67 & 138,33 & 118,33 & 130,00 & 127,33 & 121,93 & 108,33 & 125,13 & 126,59 \\
\hline 0307095 & 116,67 & 131,67 & 126,67 & 130,33 & 111,67 & 120,00 & 126,00 & 122,73 & 106,67 & 120,26 & 121,38 \\
\hline 0307131 & 120,00 & 135,67 & 125,33 & 129,67 & 110,00 & 116,67 & 140,33 & 121,20 & 101,67 & 121,36 & 122,28 \\
\hline 0307341 & 113,33 & 117,42 & 129,00 & 128,67 & 100,00 & 115,00 & 117,00 & 110,07 & 100,00 & 112,73 & 114,50 \\
\hline 0307343 & 106,67 & 116,17 & 119,00 & 130,67 & 103,33 & 113,33 & 133,00 & 111,60 & 96,67 & 112,47 & 114,49 \\
\hline 0307401 & 111,67 & $109,92^{2}$ & 119,00 & 122,00 & 126,33 & 137,33 & 124,00 & 107,00 & 96,67 & 116,49 & 117,10 \\
\hline 0307421 & 115,00 & 113,08 & 120,67 & 123,67 & 103,33 & 111,67 & 123,00 & 108,80 & 101,67 & 112,15 & 113,43 \\
\hline 0307509 & 126,67 & 150,83 & 153,67 & 130,00 & 131,67 & 138,33 & 145,00 & 134,80 & 125,00 & 138,25 & 137,33 \\
\hline 0307511 & 118,33 & 137,42 & 147,33 & 137,33 & 123,33 & 125,00 & 148,00 & 125,33 & 123,33 & 131,01 & 131,71 \\
\hline 0307541 & 113,33 & 114,61 & 124,00 & 130,00 & 106,67 & 121,67 & 131,33 & 118,07 & 106,67 & 117,04 & 118,48 \\
\hline 0307561 & 113,33 & 120,00 & 125,67 & 131,00 & 108,33 & 116,67 & 118,33 & 114,87 & 110,00 & 115,90 & 117,58 \\
\hline 0307651 & 125,00 & 135,69 & 142,67 & 132,33 & 126,67 & 136,67 & 142,33 & 128,53 & 125,00 & 132,82 & 132,77 \\
\hline 0307671 & 126,67 & 136,33 & 141,67 & 144,33 & 126,67 & 133,33 & 148,67 & 138,73 & 126,67 & 134,84 & 135,90 \\
\hline 0307689 & 121,67 & 136,86 & 152,67 & 160,33 & 140,00 & 151,67 & 155,00 & 143,93 & 126,67 & 141,06 & 143,20 \\
\hline $1 \mathrm{G} 282$ & 130,00 & 154,33 & 161,67 & 162,33 & 131,67 & 146,67 & 157,67 & 171,60 & 121,67 & 146,91 & 148,62 \\
\hline BRS 308 & 110,00 & 124,67 & 121,67 & 125,33 & 113,33 & 116,67 & 131,67 & 116,27 & 108,33 & 117,83 & 118,66 \\
\hline BRS 330 & 120,00 & 122,17 & 135,00 & 131,67 & 115,00 & 123,33 & 129,33 & 128,80 & 123,33 & 124,62 & 125,40 \\
\hline $\mathrm{DMS}^{1}$ & - & 19,74 & 30,88 & 6,24 & 20,33 & 20,68 & 31,33 & 27,81 & 29,64 & 9,16 & - \\
\hline Maior & 130,00 & 154,33 & 161,67 & 162,33 & 140,00 & 151,67 & 157,67 & 171,60 & 126,67 & 146,91 & 148,62 \\
\hline Menor & 106,67 & 109,92 & 119,00 & 117,33 & 100,00 & 111,67 & 117,00 & 107,00 & 96,67 & 112,15 & 113,11 \\
\hline Média G & 118,27 & 128,22 & 130,85 & 133,39 & 117,05 & 125,69 & 135,08 & 122,97 & 111,27 & 123,68 & 124,75 \\
\hline Média H & 120,00 & 133,72 & 139,45 & 139,78 & 120,00 & 128,89 & 139,56 & 138,89 & 117,78 & 129,79 & 130,89 \\
\hline Média T & 118,03 & 128,30 & 129,68 & 132,51 & 116,65 & 125,26 & 134,47 & 120,80 & 110,38 & 122,84 & 123,92 \\
\hline
\end{tabular}

Média G, H e T: correspondem a média geral, de híbridos experimentais e das testemunhas respectivamente; ${ }^{+} \mathrm{e}^{++}$médias de todos ambientes, com exceção de Itumbiara e sem exceção, respectivamente; ${ }^{1} \mathrm{DMS}$ para avaliação das médias na coluna; Média com sublinhado tracejado corresponde a maior média ou uma média que seja, estatisticamente igual à maior e, estatisticamente, superior a todas as médias que a maior média foi superior; Média com sublinhado contínuo: segue o mesmo raciocínio do sublinhado tracejado, porém com as menores médias. 
Os híbridos 0307671 e 0307511 se destacaram em Guaíra, SP e em Vilhena, RO, respectivamente, por terem apresentado médias estatisticamente inferiores a todas as cultivares para dias entre a semeadura e o florescimento. O híbrido 0307671 também foi o mais precoce em Teresina, PI. Outros híbridos que se destacaram para florescimento foram 0307511 , 0307561 e 0307689 , por terem apresentado as menores médias nos locais Vilhena, RO, Água Comprida, MG e Campos dos Goytacazes, RJ, respectivamente.

Considerando a média de todos os ambientes, com exceção de Teresina, PI, que não foi incluso na análise conjunta, os híbridos 0307671, 0307689, 0307421 e 0307063 se destacaram por apresentarem média, estatisticamente, inferior a todas as cultivares para florescimento. Resultados semelhantes a esse trabalho foram observados por Heckler (2002), enquanto Mariguele \& Silva (2002) e Silva et al. (2009) observaram menores e maiores médias, respectivamente (Tabela 5).

Pela análise estatística das médias em cada ambiente para rendimento de grãos (Tabela 6), podemos destacar o bom desempenho da cultivar $1 \mathrm{G} 282$ em Guaíra, SP, Sete Lagoas, MG e Vilhena, RO. Outra cultivar que se destacou foi a BRS 308, sendo a mais produtiva em Guaíra-SP e Vilhena-RO. Também podem ser destacadas as altas produtividades dos híbridos 037001 e 0009061, respectivamente em Guaíra, SP e Vilhena, RO, e dos híbridos 0307131, 0307651 e 0307071 em Teresina, PI.

Ao avaliar o desempenho dos híbridos, considerando-se a média de todos os ambientes, a cultivar 1G282 se destacou por apresentar a maior produtividade de grãos. Os genótipos BRS 308 e 0009061 apresentaram a segunda e a terceira maiores médias respectivamente, não diferindo estatisticamente da cultivar mais produtiva. Entretanto, também não diferiram de genótipos menos produtivos que a cultivar $1 \mathrm{G} 282$.

Os experimentos conduzidos em Água Comprida, MG, Rio Verde, GO e Montividiu, GO foram implantados após um cultivo comercial de soja. Com isso, é suposto que as condições do solo foram favoráveis no que se refere à estrutura e à disponibilidade de nitrogênio, uma vez que a soja se associa a bactérias do gênero Bradyrhizobium e estas captam nitrogênio da atmosfera e disponibilizam para as plantas. Contudo, vale ressaltar que, em nenhum desses experimentos, foi observado efeito significativo de híbridos a $5 \%$ pelo teste $\mathrm{F}$ para a variável produção de grãos.

Em Teresina, PI, foram observadas as maiores médias para rendimento de grãos. Esses resultados foram devidos à alta disponibilidade e à distribuição hídrica desse local. Nos outros locais em que foi avaliada essa característica, o suprimento hídrico foi adequado na fase vegetativa. Porém, essa condição não se manteve na época da fase de florescimento, o que caracteriza a maior parte dos ambientes de safrinha. De acordo com o trabalho de Lima et al. (2011), o estresse hídrico, na fase de florescimento do sorgo granífero, foi o que mais acarretou perda de produtividade de grãos.

A maioria dos híbridos apresentou produtividade média de grãos acima da média brasileira, que atualmente é estimada em $2664 \mathrm{~kg} \mathrm{ha}^{-1}$ (Conab, 2013). Albuquerque et al. (2011), avaliando cultivares de sorgo granífero em condições semiáridas, observaram produtividade de grãos com valores entre 5500 e $7000 \mathrm{~kg} \mathrm{ha}^{-1}$ em um ano chuvoso e, em um ano com baixa disponibilidade pluviométrica, valores inferiores a $3000 \mathrm{~kg} \mathrm{ha}^{-1}$.

Mariguele \& Silva (2002) observaram média geral para rendimento de grãos de $7960 \mathrm{~kg} \mathrm{ha}^{-1}$. 
TABELA 5. Médias de 25 híbridos de sorgo granífero e diferenças mínimas significativas (DMS) pelo teste de Tukey a 5\% de significância para florescimento em dias, nos locais Água Comprida-MG (AC), Campos dos Goytacazes-RJ (CG) Guaíra-SP (GUA), Itumbiara-GO (ITU), Sete Lagoas-MG (SL), Teresina-PI (TER) e Vilhena-RO (VIL), em 2011.

\begin{tabular}{|c|c|c|c|c|c|c|c|c|c|c|c|}
\hline \multirow{2}{*}{ Híbridos } & \multicolumn{9}{|c|}{ Locais } & \multirow{2}{*}{ Média $^{+}$} & \multirow{2}{*}{ Média $^{++}$} \\
\hline & $\mathrm{AC}$ & $\mathrm{CG}$ & GUA & ITU & MON & $\mathrm{RV}$ & SL & TER & VIL & & \\
\hline 0009061 & 60,33 & 65,33 & 59,00 & 64,33 & 67,67 & 56,00 & 53,67 & 61,72 & 60,90 & 123,79 & 125,52 \\
\hline 0144013 & 60,67 & 67,67 & 58,67 & 65,33 & 67,33 & 56,67 & 54,33 & 62,33 & 61,52 & 122,12 & 123,73 \\
\hline 0307001 & 61,33 & 68,33 & 60,00 & 66,67 & 67,33 & 57,00 & 56,67 & 63,39 & 62,48 & 112,59 & 113,11 \\
\hline 0307047 & 62,00 & 68,33 & 59,00 & 65,00 & 67,67 & 56,67 & 54,00 & 62,67 & 61,81 & 118,72 & 118,90 \\
\hline 0307061 & 60,67 & 68,67 & 59,33 & 64,33 & 67,33 & 55,00 & 54,33 & 62,44 & 61,38 & 122,95 & 123,47 \\
\hline 0307063 & 60,67 & 66,33 & 58,00 & 64,67 & 67,33 & 55,33 & 53,00 & 61,67 & 60,76 & 117,24 & 118,65 \\
\hline 0307071 & 61,00 & 69,33 & 60,00 & 66,67 & 67,33 & 59,00 & 54,00 & 63,06 & 62,48 & 128,40 & 129,91 \\
\hline 0307087 & 61,00 & 66,67 & 59,00 & 67,00 & 68,00 & 55,00 & 53,00 & 62,44 & 61,38 & 125,23 & 126,13 \\
\hline 0307091 & 63,00 & 70,33 & 60,67 & 69,33 & 68,33 & 58,00 & 56,00 & 64,61 & 63,67 & 125,13 & 126,59 \\
\hline 0307095 & 61,67 & 69,33 & 62,67 & 68,33 & 68,00 & 58,33 & 58,67 & 64,78 & 63,86 & 120,26 & 121,38 \\
\hline 0307131 & 61,00 & 68,67 & 60,00 & 66,33 & 67,33 & 58,33 & 56,00 & 63,22 & 62,52 & 121,36 & 122,28 \\
\hline 0307341 & 62,00 & 67,33 & 58,67 & 65,33 & 67,67 & 56,33 & 53,67 & 62,44 & 61,57 & 112,73 & 114,50 \\
\hline 0307343 & 60,33 & 66,00 & 59,00 & 65,67 & 67,33 & 57,33 & 53,33 & 61,94 & 61,29 & 112,47 & 114,49 \\
\hline 0307401 & 60,67 & 67,67 & 60,00 & 63,33 & 66,67 & 58,67 & 55,67 & 62,33 & 61,81 & 116,49 & 117,10 \\
\hline 0307421 & 60,33 & 66,33 & 59,33 & 63,00 & 67,33 & 53,00 & 53,33 & 61,61 & 60,38 & 112,15 & 113,43 \\
\hline 0307509 & 62,33 & 68,33 & 59,00 & 67,00 & 67,33 & 55,67 & 52,67 & 62,78 & 61,76 & 138,25 & 137,33 \\
\hline 0307511 & 61,33 & 69,67 & 59,67 & 65,00 & 68,33 & 56,33 & 51,33 & 62,56 & 61,67 & 131,01 & 131,71 \\
\hline 0307541 & 60,67 & 67,67 & 59,67 & 64,67 & 67,00 & 59,00 & 53,67 & 62,22 & 61,76 & 117,04 & 118,48 \\
\hline 0307561 & $60,00^{2}$ & 66,33 & 60,00 & 65,33 & 67,33 & 56,00 & 53,33 & 62,06 & 61,19 & 115,90 & 117,58 \\
\hline 0307651 & 61,33 & 67,67 & 58,67 & 67,67 & 67,33 & 57,00 & 53,67 & 62,72 & 61,90 & 132,82 & 132,77 \\
\hline 0307671 & 62,00 & 64,67 & 56,67 & 64,33 & 65,00 & 66,00 & 53,33 & 61,00 & 61,71 & 134,84 & 135,90 \\
\hline 0307689 & 61,00 & 64,33 & 57,33 & 64,33 & 67,00 & 53,67 & 53,00 & 61,17 & 60,10 & 141,06 & 143,20 \\
\hline $1 \mathrm{G} 282$ & 61,67 & 67,00 & 60,00 & 67,00 & 68,67 & 56,67 & 56,33 & 63,44 & 62,48 & 146,91 & 148,62 \\
\hline BRS 308 & 61,67 & 70,33 & 63,67 & 69,67 & 67,67 & 55,33 & 56,67 & 64,94 & 63,57 & 117,83 & 118,66 \\
\hline BRS 330 & 63,33 & 69,00 & 60,33 & 66,33 & 69,67 & 53,33 & 59,00 & 64,61 & 63,00 & 124,62 & 125,40 \\
\hline $\mathrm{DMS}^{1}$ & 3,25 & 3,79 & 2,87 & - & - & - & 4,45 & 1,76 & - & 9,16 & - \\
\hline Maior & 63,33 & 70,33 & 63,67 & 69,67 & 69,67 & 66,00 & 59,00 & 64,94 & 63,86 & 146,91 & 148,62 \\
\hline Menor & 60,00 & 64,33 & 56,67 & 63,00 & 65,00 & 53,00 & 51,33 & 61,00 & 60,10 & 112,15 & 113,11 \\
\hline Média G & 61,28 & 67,65 & 59,53 & 65,87 & 67,52 & 56,79 & 54,51 & 61,96 & 61,88 & 123,68 & 124,75 \\
\hline Média H & 61,21 & 67,50 & 59,29 & 65,62 & 67,36 & 57,02 & 54,12 & 62,51 & 61,72 & 129,79 & 130,89 \\
\hline Média T & 62,22 & 68,78 & 61,33 & 67,67 & 68,67 & 55,11 & 57,33 & 64,33 & 63,02 & 122,84 & 123,92 \\
\hline
\end{tabular}

Média G, H e T: correspondem a média geral, de híbridos experimentais e das testemunhas respectivamente; ${ }^{+} \mathrm{e}^{++}$médias de todos ambientes, com exceção de Itumbiara e sem exceção, respectivamente; ${ }^{1} \mathrm{DMS}$ para avaliação das médias na coluna; Média com sublinhado tracejado corresponde a maior média ou uma média que seja, estatisticamente igual à maior e, estatisticamente, superior a todas as médias que a maior média foi superior; Média com sublinhado contínuo: segue o mesmo raciocínio do sublinhado tracejado, porém com as menores médias. 
TABELA 6. Médias de 25 híbridos de sorgo granífero e diferenças mínimas significativas (DMS) pelo teste de Tukey a 5\% de significância para rendimento de grãos em kg ha-1 nos locais Água Comprida, MG (AC), Guaíra, SP (GUA), Montividiu, GO (MON), Rio Verde,GO (RV), Sete Lagoas, MG (SL), Teresina, PI (TER) e Vilhena, RO (VIL) em 2011.

\begin{tabular}{|c|c|c|c|c|c|c|c|c|}
\hline \multirow{2}{*}{ Híbridos } & \multicolumn{7}{|c|}{ Locais } & \multirow{2}{*}{ Média } \\
\hline & $\mathrm{AC}$ & GUA & MON & $\mathrm{RV}$ & $\mathrm{SL}$ & TER & VIL & \\
\hline 0009061 & 4014,83 & 4298,70 & 3553,13 & 6207,66 & 4722,61 & 6121,16 & 4367,13 & 4755,03 \\
\hline 0144013 & 4179,85 & 3545,29 & 3808,25 & 5679,83 & 4838,23 & 5846,33 & 3735,68 & 4519,06 \\
\hline 0307001 & 3749,66 & 4793,62 & 2795,82 & 5965,37 & 4499,54 & 6232,22 & 2878,93 & 4416,45 \\
\hline 0307047 & 3871,57 & 4362,79 & 3746,48 & 6403,13 & 4076,84 & 6304,68 & 3460,47 & 4603,71 \\
\hline 0307061 & 4271,11 & 4658,15 & 3036,16 & 5744,54 & 4832,06 & 5863,60 & 4118,71 & 4646,33 \\
\hline 0307063 & 4171,95 & 3882,61 & 2959,91 & 5880,17 & 4407,07 & 6561,79 & 3624,58 & 4498,30 \\
\hline 0307071 & 3734,29 & 4292,96 & 3825,44 & 6307,92 & 4145,86 & 7149,56 & 2520,99 & 4568,14 \\
\hline 0307087 & 3710,73 & 3848,66 & 3982,91 & 6717,03 & 3861,10 & 6637,93 & 3494,91 & 4607,61 \\
\hline 0307091 & 3929,81 & $2658,89^{2}$ & 4070,35 & 6065,08 & 3009,38 & 5183,39 & 2719,09 & 3948,00 \\
\hline 0307095 & 3344,87 & 4079,86 & 2920,06 & 5698,54 & 3204,07 & 5844,80 & 2215,48 & 3901,10 \\
\hline 0307131 & 3689,20 & 2586,90 & 2914,65 & 6014,44 & 3528,57 & 7622,18 & 2508,87 & 4123,54 \\
\hline 0307341 & 3789,73 & 4071,33 & 2905,04 & 6027,37 & 3814,80 & 6689,55 & 3788,74 & 4440,94 \\
\hline 0307343 & 4168,51 & 4439,93 & 2776,73 & 6400,75 & 4163,82 & 5882,02 & 4166,22 & 4571,14 \\
\hline 0307401 & 4023,68 & 3150,88 & 2393,94 & 5633,66 & 2919,78 & 6718,42 & 3477,89 & 4045,46 \\
\hline 0307421 & 3565,75 & 4721,50 & 3157,69 & 5066,58 & 4960,38 & 6170,77 & 4247,98 & 4555,81 \\
\hline 0307509 & 3082,68 & 2902,83 & 3211,57 & 5659,61 & 2864,25 & 6421,76 & 2476,36 & 3802,72 \\
\hline 0307511 & 4104,75 & 3067,82 & 2804,19 & 5919,77 & 3311,36 & 6725,22 & 2645,89 & 4082,71 \\
\hline 0307541 & 3770,84 & 4391,56 & 2579,13 & 6195,92 & 4156,58 & 6049,61 & 4010,28 & 4450,56 \\
\hline 0307561 & 3995,67 & 4469,44 & 3008,56 & 6003,95 & 4139,83 & 6242,81 & 4141,80 & 4571,72 \\
\hline 0307651 & 3406,90 & 3592,79 & 3187,22 & 5943,46 & 3967,70 & 7192,40 & 2899,22 & 4312,81 \\
\hline 0307671 & 3843,91 & 3338,97 & 3786,06 & 5336,16 & 4555,23 & 6514,21 & 3490,78 & 4409,33 \\
\hline 0307689 & 3897,82 & 2982,80 & 3399,12 & 5184,41 & 4216,36 & 6919,81 & 3809,56 & 4344,27 \\
\hline $1 \mathrm{G} 282$ & 3880,31 & 5012,35 & 3753,74 & 5600,24 & 5575,03 & 6553,11 & 4384,84 & 4965,66 \\
\hline BRS 308 & 4410,34 & 5112,08 & 4071,53 & 5652,82 & 4242,48 & 5086,83 & 4858,74 & 4776,40 \\
\hline BRS 330 & 2945,17 & 3820,46 & 2960,79 & 5730,39 & 4436,20 & 6349,22 & 3472,94 & 4245,02 \\
\hline $\mathrm{DMS}^{1}$ & - & 1799,59 & - & - & 2125,58 & 1879,10 & 1724,65 & 721,65 \\
\hline Maior & 4410,34 & 5112,08 & 4071,53 & 6717,03 & 5575,03 & 7622,18 & 4858,74 & 4965,66 \\
\hline Menor & 2945,17 & 2586,90 & 2393,94 & 5066,58 & 2864,25 & 5086,83 & 2215,48 & 3802,72 \\
\hline Média G & 3822,16 & 3923,33 & 3264,34 & 5881,55 & 4097,97 & 6355,33 & 3500,64 & 4406,47 \\
\hline Média H & 3832,64 & 3879,97 & 3219,20 & 5911,61 & 4008,88 & 6404,28 & 3399,98 & 4371,58 \\
\hline Média T & 3745,27 & 4648,30 & 3595,35 & 5661,15 & 4751,24 & 5996,39 & 4238,84 & 4662,36 \\
\hline
\end{tabular}

Média G, H e T: correspondem a média geral, de híbridos experimentais e das testemunhas respectivamente; ${ }^{+} \mathrm{e}^{++}$médias de todos ambientes, com exceção de Itumbiara e sem exceção, respectivamente; ${ }^{1}$ DMS para avaliação das médias na coluna; Média com sublinhado tracejado corresponde a maior média ou uma média que seja, estatisticamente igual à maior e, estatisticamente, superior a todas as médias que a maior média foi superior; Média com sublinhado contínuo: segue o mesmo raciocínio do sublinhado tracejado, porém com as menores médias. 
Heckeler (2002) observou produtividade variando de 4736 a $9865 \mathrm{~kg} \mathrm{ha}^{-1}$. Silva et al. (2009) observaram a média geral de $2810 \mathrm{~kg} \mathrm{ha}^{-1}$ das cultivares em Montividiu, GO; em Rio Verde, GO, houve médias entre 640 a $1696 \mathrm{~kg} \mathrm{ha}^{-1}$; e, em Santa Helena, GO, as médias variaram de 773 a $2060 \mathrm{~kg} \mathrm{ha}^{-1}$.

Pelo índice de confiança de Annichiarico (1992), os híbridos de maior destaque foram respectivamente 1G282, BRS 308, 0009061, 0309061, 0307061, 0307047, 0307561, 0307087, 0144013, 0144013, 0307421, 0307343 e 0307063 . No caso desses híbridos serem plantados nos locais avaliados, é de se esperar que apresentem médias, respectivamente, 10,$63 ; 7,04 ; 6,90 ; 3,66 ; 3,00 ; 1,86 ; 1,48 ; 1,13$; 0,$99 ; 0,92$ e $0,19 \%$ superiores à média do determinado ambiente (Figura 2).
Para a seleção de híbridos, considerando vários locais e interação entre genótipos e ambientes significativa, o método de Annichiarico (1992) é mais indicado que a avaliação exclusiva das médias, pois seu índice agrega os conceitos de adaptabilidade geral e estabilidade de comportamento, segundo Cruz e Carneiro (2006).

De acordo com Mariotti et al. (1976), adaptabilidade é a capacidade do indivíduo responder vantajosamente às condições ambientais submetidas, enquanto estabilidade está associada ao comportamento previsível do genótipo diante da variação ambiental. A estabilidade pode ser devida à não variação do genótipo ou com a variação coerente com a variação ambiental. Essa última é classificada como estabilidade agronômica ou de comportamento.

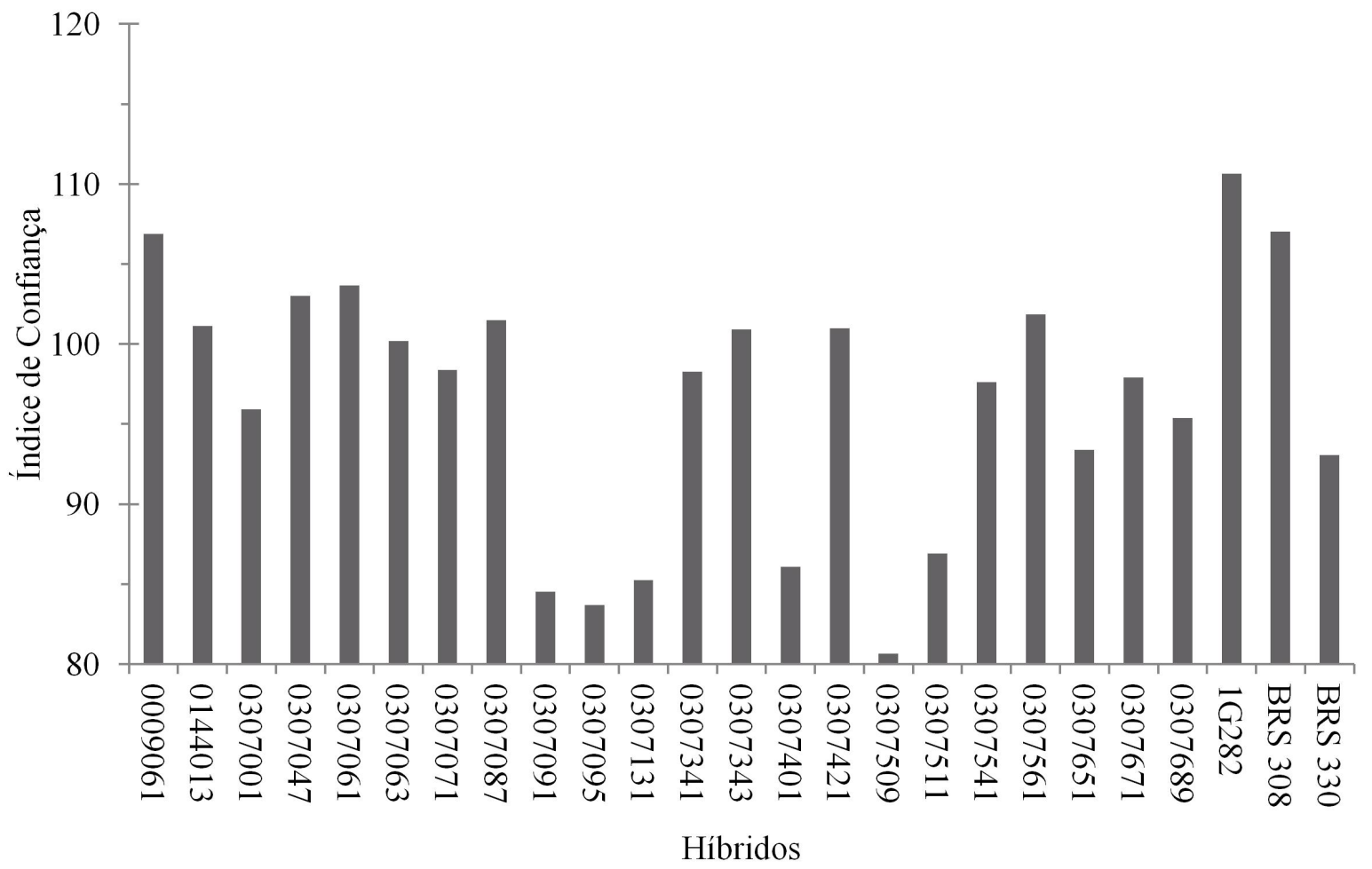

FIGURA 2. Índice de confiança proposto por Annichiarico (1992) para a característica rendimento de grãos avaliada nos locais Água Comprida, MG, Guaíra, SP, Montividiu, GO, Rio Verde, GO, Sete Lagoas, MG, Teresina, PI e Vilhena, RO, em 2011. 


\section{Agradecimentos}

À Faperj e à (Capes), pelas bolsas de mestrado concebidas, e à Fapemig, pelo apoio financeiro para execução desta pesquisa.

\section{References}

AGRITEMPO. Disponível em: <www.agritempo. gov.br>. Acesso em: 10 dez. 2013.

ALBUQUERQUE, C. J. B.; VON PINHO, R. G.; RODRIGUES, J. A. S.; BRANT, R. S.; MENDES, M. C. Espaçamento e densidade de semeadura para cultivares de sorgo granífero no semiárido. Bragantia, Campinas, v. 70, p. 278-285, 2011

CONAB. Disponível em <www.conab.gov.br. Acesso em: 03 abr. 2013.

CROMARTY, A. S.; ELLIS, R. H.; ROBERTS, E. H. Design of seed storage facilities for genetic conservation. Rome: International Board of Plant Genetic Resources, 1985. 100 p.

CRUZ, C. D. Programa Genes: Biometria. Viçosa, MG: UFV, 2006. 382 p.

CRUZ, C. D.; CARNEIRO, P. C. S. Modelos biométricos aplicados ao melhoramento genético. Viçosa, MG: UFV, 2006. 585 p.

FERREIRA, D. F. SISVAR: um programa para análises e ensino de estatística. Revista Cientifica Symposium, Lavras, v. 6, p. 3641, 2008.

GARCIA, R. G.; MENDES, A. A.; COSTA, C.; PAZ, I. C. L. A.; TAKAHASHI, S. E.; PELÍCIA, K. P.; KOMIYAMA, C. M.; QUINTEIRO R. R. Desempenho e qualidade da carne de frangos de corte alimentados com diferentes níveis de sorgo em substituição ao milho. Arquivo
Brasileiro de Medicina Veterinária e Zootecnia, Belo Horizonte, v. 57, p. 634-643, 2005.

GOBESSO, A. A. O.; D’AURIA, E.; PREZOTTO, L. D.; RENNO, F. P. Substituição de milho por sorgo triturado ou extrusado em dietas para equinos. Revista Brasileira de Zootecnia, Viçosa, MG. v. 37, p. 2011-2016, 2008.

GOES, R. J.; RODRIGUES, R. A. F.; ARF, O.; ARRUDA, O. G.; VILELA, R. G. Fontes e doses de nitrogênio em cobertura no sorgo granífero na safrinha. Revista Brasileira de Milho e Sorgo, Sete Lagoas, v. 10, p. 121129, 2011.

GOMES, F. P. Curso de estatística experimental. 15. ed. Piracicaba: FEALQ, 2009. 451 p.

GOOLE EARTH MAPAS. Disponivel em: $<$ http://:mapas.google.com.> Acesso em: 3 jun 2013

HECKLER, J. C. Sorgo e girassol no outonoinverno, em sistema plantio direto, no Mato Grosso do Sul, Brasil. Ciência Rural, Santa Maria, v. 32, p. 517-520, 2002.

LIMA, N. R. C. B.; SANTOS, P. M.; MENDONÇA, F. C.; ARAÚJO, L. C. Critical periods of sorghum and palisadegrass in intercropped cultivation for climatic risk zoning. Revista Brasileira de Zootecnia, Viçosa, MG, v. 40, p. 1452-1457, 2011.

LOPES, S. J.; STORCK, L.; LÚCIO, A. D.; LORENTZ, L. H.; LOVATO, C.; DIAS, V. O. Tamanho de parcela para produtividade de grãos de sorgo granífero em diferentes densidades de plantas. Pesquisa Agropecuária Brasileira, Brasília, DF, v. 40, p. 525-530, 2005.

MARIGUELE, K. H.; SILVA, P. S. L. Avaliação dos 
rendimentos de grãos e forragem de cultivares de sorgo granífero. Caatinga, Mossoró, v. 15, p. 13-18, 2002.

MARIOTTI, J. A.; OYARZABAL, E. S.; OSA, J. M.; BULACIO, A. N. R.; ALMADA, G. H. Análisis de estabilidad y adaptabilidad de genótipos de caña de azucar. I. Interacciones dentro de una localidad experimental. Revista Agronómica del Noroeste Argentino, Tucuman, v. 13, p. 105-127, 1976.

MUTISYA, J.; SUN, C.; ROSENQUIST, S.; BAGUMA, Y.; JANSSON, C. Diurnal oscillation of SBE expression in sorghum endosperm. Journal of Plant Physiology, Stuttgart, v. 166 p. 428-434, 2009.

OLEMBO, K. N.; M'MBOYI, F.; KIPLAGAT, S.; SITIENEY, J. K.; OYUGI, F. K.; Sorghum Breeding in Sub-Saharan Africa: The success stories. Nairobi: African
Biotechnology Stakeholders Forum, 2010. 40 p.

RODRIGUES, J. A. S. Cultivo do Sorgo. 6. ed. Sete Lagoas: Embrapa Milho e Sorgo, 2010. (Embrapa Milho e Sorgo. Sistema de produção, 2). Disponível: < http://www. cnpms.embrapa.br/publicacoes/sorgo_6_ed/ index. htm>. Acesso em: 10 fev. 2011.

SANTOS, F. G. Cultivares de Sorgo. Sete Lagoas: Embrapa Milho e Sorgo, 2003. 3 p. (Embrapa Milho e Sorgo. Comunicado técnico, 77)

SILVA, A. G.; BARROS, A. S.; SILVA, L. H. C. P.; MORÃES, E. B.; PIRES, R.; TEIXEIRA, I. R. Avaliação de cultivares de sorgo granífero na safrinha no sudoeste do Estado de Goiás. Pesquisa Agropecuária Tropical, Goiânia, v. 39, p. 168-174, 2009.

SINDIRAÇÕES. Disponível em: <www.sindiracoes. org.br. Acesso em: 4 abr. 2013. 